\title{
A Demographic Study of Information Technology Professionals' Organizational Citizenship Behavior
}

\author{
Shih Yung Chou (Corresponding author) \\ HEB School of Business and Administration, University of the Incarnate Word \\ 4301 Broadway, CPO 394, San Antonio, TX 78209, United States \\ Tel: 1-210-283-6482Ｅ-mail: chou@uiwtx.edu
}

\author{
John Pearson \\ College of Business, Southern Illinois University Carbondale \\ 1025 Lincoln Dr., Carbondale, IL 62901, United States
}

Tel: 1-618-453-7802 E-mail: jpearson@business.siuc.edu

Received: March 31, 2011 Accepted: April 10, 2011 doi:10.5296/jmr.v3i2.625

\begin{abstract}
Organizational citizenship behavior (OCB) has been suggested to facilitate organizational functioning. However, previous research has found that information technology (IT) professionals exhibit significantly lower OCB than non-IT professionals. To explain this phenomenon, this research includes demographic variables including age, gender, and tenure and examines their impact on the OCB of these highly skilled professionals. Using IT professionals as the unit of analysis with a sample size of 85 , the results indicate that age and tenure are significant predictors of an IT professional's OCB. Results of this research can be used by organizations and managers to establish a work environment where OCB is encouraged.
\end{abstract}

Keywords: Organizational citizenship behavior, Information technology professionals, Organizational demography 


\section{Introduction}

Because of increasing competition, many organizations have recognized the effect of employee behaviors on organizational functioning (Sparrowe, Liden, Wayne, \& Kraimer, 2001). Among the various employee behaviors, work behavior is often used to predict individual, group, and organizational performance (Bateman \& Organ, 1983; Organ, 1988). Organ (1988) has suggested that organizational functioning is facilitated when employees go beyond formal role requirements that are not explicitly required by job descriptions and formal reward systems. This particular type of employee behavior has been labeled by Bateman and Organ (1983) and Smith, Organ, and Near (1983) as "organizational citizenship behavior" (OCB).

OCB is important because organizations typically are unable to anticipate the range of behaviors needed for the achievement of organizational goals through formal job descriptions (Vanyperen \& Van Den Berg, 1999). Moreover, OCB provides organizations with additional resources and eliminates the need for formal mechanisms that are crucial to successful organizational functioning (Bogler \& Somech, 2004). Given the perceived importance of $\mathrm{OCB}$, the number of studies related to OCB has increased dramatically (Podsakoff, Mackenzie, Paine, \& Bachrach, 2000).

Despite the amount of OCB research has increased, two important areas still need to be addressed. First, when comparing OCB exhibited by IT professionals and non-IT professionals, Moore and Love (2005) discovered that IT professionals tended to demonstrate significantly lower OCB than professionals in non-IT areas. Moore and Love's study, therefore, suggests an opportunity to investigate factors that influence an IT professional's OCB. Second, previous OCB research has examined how demographic variables influence an individual's OCB in various contexts. However, most of this research attention has been paid to OCB exhibited by human service professionals such as restaurant employees (e.g., Stamper \& Van Dyne, 2001), nurses (e.g., Altuntas \& Baykal, 2010), teachers (e.g., Belogolovsky \& Somech, 2010), service workers (Felfe \& Heinitz, 2010), or military personnel (e.g., Gurbuz, 2009). Very little attention has been paid to non-human service professionals such as IT professionals who are not necessarily required emotional involvement with other people (Golembiewski \& Munzenrider, 1988). Thus, the major objective of this research is to examine how demographic variables including age, gender, and tenure influence OCB exhibited by an IT professional. The results of this research, therefore, may help organizations and managers manage a diverse organizational environment where OCB can naturally occur. Figure 1 shows the proposed research model.

The remainder of the research is organized as follows. We first investigate previous research in the area of OCB. This is followed by the theoretical arguments for the proposed research model. Next, we present the procedures of testing the proposed research model empirically. Then, the results of the empirical test of the model are presented. Finally, we provide a discussion of the findings, followed by limitations, contributions, and suggestions for future research. 


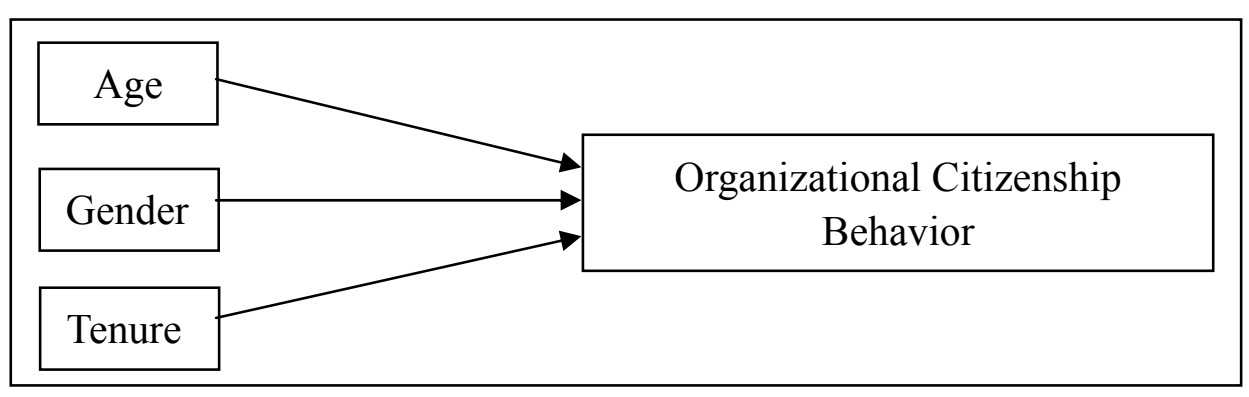

Figure 1. Proposed Research Model.

\section{Theoretical Framework and Research Hypotheses}

Following Organ, Podsakoff, and MacKenzie's (2006) definition, OCB in this research is defined as "individual behavior that is discretionary, not directly or explicitly recognized by the formal reward system, and in the aggregate promotes the efficient and effective functioning of the organization" (p. 3), which consists of five distinct dimensions including altruism, courtesy, sportsmanship, conscientiousness, and civic virtue. According to Moorman (1993), altruism is the behavior of helping a specific person with an organizationally relevant task or problem. Courtesy occurs when an individual engages in preventing a work-related problem from occurring and involves actions like touching base with those parties whose work would be affected by one's decisions. Sportsmanship is the behavior that entails avoiding excessive complaining or railing against mostly imaged slights. Conscientiousness is the behavior that allows one to carry out his or her specific role requirement to levels well beyond those normally expected. Civic virtue is the behavior that evolves around responsible participation in the political life of the organization.

Research in OCB has predominately focused on antecedents of OCB. For example, Lambert (2000) examined OCB in a manufacturing setting and found that perceived organizational support significantly predicted OCB. Lapierre and Hackett's (2007) meta-analytic study demonstrated that employees who were more conscientious displayed higher levels of OCB, and employees with higher levels of job satisfaction demonstrated more OCB. Chiaburu and Lim (2008) tested whether manager trustworthiness and interactional justice predict OCB and found that perceived interactional justice and manager trustworthiness were the antecedents of OCB.

In addition to antecedents of $\mathrm{OCB}$, researchers have examined the consequences of OCB extensively. For instance, a longitudinal study conducted by Koys (2001) found that OCB had a significant impact on profitability. Ehrhart, Bliese, and Thomas (2006) discovered that unit-level OCB was related to unit effectiveness. Whiting, Podsakoff, and Pierce (2008) reported that OCB had a significant effect on performance evaluation decisions.

\subsection{Age and Organizational Citizenship Behavior}

As Caspi and Roberts (1990) has pointed out, age has a significant impact on intelligence and cognitive development of an individual. Using this rationale, Wagner and Rush (2000) claimed that age might lead to important changes in the motivational bases or antecedents associated with OCB. Thus, one can expect that there is a potential relationship between an 
individual's age and OCB.

Several previous empirical studies have investigated the age-OCB relationship. For example, Li and Wan (2007) investigated how age influences an individual's perception of OCB as in-role behavior or as extra-role behavior in a Chinese context. These researchers revealed that OCB was associated with age and the older employees were, the more they perceived $\mathrm{OCB}$ as in-role behavior. $\mathrm{Ng}$ and Feldman (2008) conducted a meta-analysis on the relationship between age and the dimensions of job performance including OCB and found that OCB was significantly and positively related to age.

It is also suggested that older employees tend to have lower needs for achievement and higher needs for affiliation than do younger employees (Doering, Rhodes, \& Schuster, 1983). Moreover, Kanungo and Conger (1993) claimed individuals coordinate their behaviors in an interpersonal transactional way and the further development of these behaviors focuses on meeting mutual and moral obligations. In other words, the increase of age could shift an individual's behavior from competing to cooperating or helping. Thus, one can expect that older IT professionals will exhibit higher levels of OCB than do younger IT professionals. Based on the relationship between age and OCB, we hypothesize the following:

Hypothesis 1: Age will have a positive impact on OCB exhibited by an IT professional.

\subsection{Gender and Organizational Citizenship Behavior}

Gender is important to the study of OCB as it has been argued to have an important effect on gender specific behaviors. For instance, Heilman and Chen (2005) argued that one of the female gender stereotypes is being helpful, which is captured by the altruism sub-construct of OCB. Meanwhile, Farrell and Finkelstein (2007) suggested that civic virtue can be considered assertive and independent behavior, which is more frequently associated with the male gender stereotype.

Visualizing the potential impact of gender differences on OCB, researchers have used gender as an independent variable or a moderator to examine its impact on OCB. For instance, Allen (2006) investigated the relationships among OCB to the organization, salary, and promotion using gender as a moderator. The results indicated that gender moderated the relationship between OCB to the organization and promotion and the relationship was stronger for males than for females. Farrell and Finkelstein (2007) conducted three laboratory studies and demonstrated that OCB in general was expected more of women than of men. The results also indicated that civic virtue behaviors were exhibited more by men than by women. In a study that examined the relationships between OCB and knowledge sharing, Lin (2008) demonstrated that the impact of altruism on knowledge sharing was stronger for women than for men, whereas the impacts of courtesy and sportsmanship on knowledge sharing were stronger for men than for women.

Despite the previous research findings on gender-OCB relationship, it has been shown that IT workforces have been dominating by men (Trauth, Nielsen, \& Von Hellens, 2003). In addition, it is suggested that IT occupations are traditionally viewed as masculine occupations (Fletcher, 1994, 1998; Olsson \& Walker, 2004). Because it is suggested that males tend to 
exhibit less OCB than females, one can expect that being male in the context of IT will have a negative impact on OCB. Thus, we hypothesize the following:

Hypothesis 2: Gender, or being men, will have a negative impact on OCB exhibited by an IT professional.

\subsection{Tenure and Organizational Citizenship Behavior}

Since OCB is exhibited when an employee orients newcomers or helps others (Lepine \& Van Dyne, 2001), one can argue that an individual with more job experience would be able to assist others with less experience. Although tenure has not received much attention, compared to age and gender, by OCB researchers, it has been assessed its impact on OCB. For instance, when investigating whether OCB reduces job performance of those employees who are encouraged to adhere to pre-specified job procedures, Hunt (2002) found that OCB was positively associated with tenure. Ehigie and Otukoya (2005) examined how perceived organizational support and perceived fair interpersonal treatment relates to OCB by controlling the effect tenure and found that tenure contributed significantly to the variance of OCB. When examining group-level OCB, Choi (2009) found that diversity in tenure increases the degree of group-level OCB.

Meanwhile, it is also suggested that technical competencies related to IT are largely acquired through learning by doing (Ang, Slaughter, \& Ng, 2002), which is a reflection of an IT professional's on-the-job experience (Mithas \& Krishnan, 2008). Because IT context can be considered a fast pace environment, tenure in the job allows an IT professional to acquire more relevant IT skills and competencies, which are important resources to those IT professionals who have less job experience. As previous research has shown the positive relationship between tenure and $\mathrm{OCB}$, we hypothesize the following:

Hypothesis 3: Tenure will have a positive effect on OCB exhibited by an IT professional.

\section{Research Methodology}

\subsection{Procedure}

We employed an online cross-sectional survey approach as it provides an efficient and accurate means of assessing information about the population (Zikmund, 2003). The initial survey instrument was developed by adopting previously validated measures and was modified based on the comments from a pilot study. The survey consisted of two sections. In the first section, OCB was measured by using a 24-item questionnaire using a 7-point Likert scale with 1 representing strongly disagree and 7 representing strongly agree. It is important to note that we operationalized OCB as a formative construct. According to Moorman (1993), the internal reliability (measured by Cronbach Alpha) for altruism, courtesy, sportsmanship, conscientiousness, and civic virtue was $0.81,0.87,0.87,0.83$, and 0.77 , respectively. We obtained an aggregated OCB by averaging the scores of five OCB dimensions.

The second part of the survey was designed to solicit respondents' demographic information including age, gender, and tenure. Age was measured by years using an open-ended scale. Gender was measured by a categorical scale including male and female. Tenure was 
measured by years and intended to capture the years that an IT professional has worked in the IT profession.

\subsection{Data Collection}

A snowball sampling approach was used to reach the target population as it is suggested a viable approach when difficulties in gaining access to and recruiting target populations are experienced (Elan-Goossensen, Van De Goor, Vollemans, Hendriks, \& Garretsen, 1997). We first sent out email invitations requesting participation in this research to IT professionals at a large Midwestern university in the United States and used their personal referrals to locate other IT professionals. Personal referral was considered appropriate as it has been used widely by previous research (e.g., Martin \& Dean, 1990; Piron, 2006; Shtayermman, 2008).

A total of 165 surveys were viewed and 132 surveys were started, which resulted in a response rate of $80.00 \%$. After deleting responses with large missing values, a total of 85 responses were obtained. The relatively small sample size was not a concern as this research utilized partial least squares (PLS), which is suggested to be powerful even under the condition of small same size with non-normal data distribution (Chin, 1998; Chin, Marcolin, \& Newsted, 2003; Chin \& Newsted, 1999).

Respondents were located across 21 U.S. states and in different industries including banking, health care, education, financial, automotive, manufacturing, and retailing industry. Majority of the respondents were male (76\%) with ages ranging mostly between 26 and $35(31 \%)$ and greater than or equal to 46 years $(45 \%)$. In terms of tenure in the IT profession, $13 \%$ of respondents had been in the profession for less than or equal to 5 years, $33 \%$ of them between 5.1 and 15 years, $34 \%$ of them between 15.1 and 25 years, and $20 \%$ of them had been in the profession for more than 25 years. Table 1 summarizes this information about the respondents.

Table 1. Demographics of respondents

\begin{tabular}{|l|c|c|}
\hline \multicolumn{1}{|c|}{ Variable } & $\begin{array}{c}\text { Frequency } \\
(\mathrm{N}=85)\end{array}$ & Valid Percent \\
\hline Age $(\mathrm{N}=85, \mathrm{SD}=10.9)$ & & \\
\hline$\leq 25$ years & 2 & $2.4 \%$ \\
\hline $26-35$ years & 27 & $31.8 \%$ \\
\hline $36-45$ years & 17 & $20.0 \%$ \\
\hline$\geq 46$ years & 39 & $45.8 \%$ \\
\hline Gender $(\mathrm{N}=85)$ & 65 & \\
\hline Male & 20 & $23.5 \%$ \\
\hline Female & & \\
\hline Tenure in the profession $(\mathrm{N}=85, \mathrm{SD}=10.5)$ & 11 & $12.9 \%$ \\
\hline$\leq 5$ years & 28 & $32.9 \%$ \\
\hline $5.1-15$ years & 29 & $34.2 \%$ \\
\hline $15.1-25$ years & 17 & $20.0 \%$ \\
\hline$\geq 25.1$ years & & \\
\hline
\end{tabular}




\subsection{Descriptive Data Analysis}

Table 2 contains the correlations among five OCB dimensions, age, gender, and tenure. We also conducted a convergent analysis to analysis because of the nature of OCB. Specifically, $\mathrm{OCB}$ in our research is considered a formative construct. This means that the $5 \mathrm{OCB}$ sub-constructs cause OCB. When evaluating convergence validity of OCB covariance based estimates such as reliability and variance extracted are not applicable because formative indicators are not expected to move together and to show high covariance (Chin, 1998). Thus, the path coefficients and their associated t-statistic values were examined to check if they significantly contribute to the emergent construct as suggested by Liang, Saraf, Hu, and Xue (2007). The results of the analysis demonstrated that all five path weights were significant at the 0.01 level (see Table 3), indicating that the five sub-constructs form the construct of OCB from different significant paths.

Table 2. Correlations among major constructs

\begin{tabular}{|c|c|c|c|c|c|c|c|c|}
\hline & Age & Gender & Tenure & Alt & $\mathrm{Cou}$ & Sports & Cons & Civic \\
\hline Age & 1.000 & & & & & & & \\
\hline Gender & $0.318^{*}$ & 1.000 & & & & & & \\
\hline Tenure & $0.677 * *$ & 0.016 & 1.000 & & & & & \\
\hline Alt & $0.728 * *$ & -.121 & $.634 * *$ & 1.000 & & & & \\
\hline Cou & $.411^{* *}$ & $.369 * *$ & $.608 * *$ & $.505 * *$ & 1.000 & & & \\
\hline Sports & $.431 * *$ & $-.564 * *$ & $.717 * *$ & $.482 * *$ & $.487 * *$ & 1.000 & & \\
\hline Cons & $.612 * *$ & $-.459 * *$ & $.651 * *$ & $.537 * *$ & $.384 * *$ & $.417 * *$ & 1.000 & \\
\hline Civic & $.370 * *$ & $-.564 * *$ & $.717 * *$ & $.482 * *$ & $.487 * *$ & $.351 * *$ & $.477 * *$ & 1.000 \\
\hline \multicolumn{9}{|c|}{$\begin{array}{l}\text { Note. } * *=\text { Correlation is significant at the } 0.01 \text { level. } \\
\text { Alt: altruism; Cou: courtesy; Sports: sportsmanship; Cons: conscientiousness; Civic: civic } \\
\text { virtue }\end{array}$} \\
\hline
\end{tabular}

Table 3. Convergent analysis of OCB sub-constructs

\begin{tabular}{|c|l|c|c|c|}
\hline \multirow{2}{*}{ Construct } & \multicolumn{1}{|c|}{ Indicator } & Mean & Standard Deviation & t-value \\
\hline \multirow{3}{*}{$\begin{array}{c}\text { Organizational } \\
\text { Citizenship } \\
\text { Behavior }\end{array}$} & Altruism & 5.667 & .845 & $9.395^{*}$ \\
\cline { 2 - 5 } & Courtesy & 5.887 & .683 & $11.849^{*}$ \\
\cline { 2 - 5 } & Sportsmanship & 5.045 & .915 & $8.712^{*}$ \\
\cline { 2 - 5 } & Conscientiousness & 5.424 & 1.097 & $27.707^{*}$ \\
\cline { 2 - 5 } & Civic Virtue & 5.365 & 1.026 & $6.925^{*}$ \\
\hline \multicolumn{2}{|l}{ Note. * Significant at the 05 level }
\end{tabular}

\subsection{Hypothesis Testing}

Hypothesis 1 proposed that age will have a positive impact on OCB exhibited by an IT 
professional. Our PLS analysis provided evidence for supporting the hypothesis $1(\beta=.601, \mathrm{t}$ $=10.289, \mathrm{p}<.05)$. This means that as an IT professional becomes older, he or she demonstrates higher levels of OCB.

Hypothesis 2 proposed that gender, or being men, will have a negative impact on OCB exhibited by an IT professional. Unexpectedly, this relationship was not significant $(\beta=-.031$, $\mathrm{t}=.310, \mathrm{p}>.05)$. Although the relationship was not significant, the negative direction of the relationship was as predicted.

Hypothesis 3 proposed that tenure will have a positive effect on OCB exhibited by an IT professional. As predicted, the results showed that the tenure-OCB link was statistically significant $(\beta=.597, \mathrm{t}=8.789, \mathrm{p}<.05)$. In other words, the more IT job experience an IT professional has, the higher levels of OCB he or she exhibits.

\section{Discussion, Limitations, and Future Research Areas}

The purpose of this research was to analyze the effect of age, gender, and tenure on an IT professional's OCB. Our results demonstrated that age and tenure were significant predictors of an IT professional's OCB. These findings are consistent with previous research findings (e.g., Ehigie \& Otukoya, 2005; Li \& Wan, 2007). A managerial implication of these findings is that older IT professionals are able to promote organizational effectiveness by exhibiting OCB. Although it is suggested that IT professionals are required to constantly learn and acquire new IT related knowledge and skills (Joseph, Ng, Koh, \& Ang, 2007), the overall competencies result from being older and staying longer in the IT profession enable these IT professionals to exhibit more OCB than younger and less job experience IT professionals. Thus, managers must focus on increasing job satisfaction and reducing turnover rate of IT professionals.

Unexpectedly, our result failed to support hypothesis 2. Although previous research has shown inconsistent findings, we explain this result by stating that because we used an aggregated OCB measure, a male IT professional might exhibit more male related OCB behaviors such as civic virtue or courteous behavior. Meanwhile, female IT professionals might exhibit more altruistic behaviors than other types of male related OCB behaviors. Although this finding is consistent with Heilman and Chen's (2005) findings, it implies that managers need to create a work environment where gender can be a reinforcer for both gender-related and non gender-related OCB. For instance, managers can invite male IT professionals in meetings focusing on creating or enhancing company's image or productivity (civic virtue behavior) and assign female IT professionals in group based projects (altruistic behavior).

Although this research used sound theoretical concepts and employed suitable statistical procedures, it is not without limitations. First, because we experienced difficulties in reaching its target population, it utilized a snowball sampling approach as it was the best available approach. However, bias could occur because an IT professional referred by another IT professional to participate in this research might have a higher probability of being similar (Zikmund, 2003). However, we found that the respondents were located across 21 states in 
the U.S. with significant variability in demographic backgrounds. Thus, sample representativeness in this research could be assumed. However, future studies are still needed to validate the results of this research using probability sampling techniques with a larger sample size.

A second limitation is that this research used an online cross-sectional survey that makes it difficult to identify the direction of causality. Thus, it is important to note that the results of this research can only show the causality of the proposed model. As all cross-sectional studies suffer this limitation (Gallivan, Spitler, \& Koufaris, 2005), future longitudinal studies are needed to strengthen the proposed model.

Finally, since investigating the degree of OCB exhibited by an IT professional was the major purpose of this research, OCB was measured by a summated scale that included five sub-constructs. However, as the nature of IT jobs is relatively different from other types of occupations, one can expect that certain dimensions of OCB may be exhibited by an IT professional more often than other dimensions. For instance, because IT professionals usually possess specific knowledge and skills that are necessary for their tasks and crucial for others' job outcomes, IT professionals might exhibit more altruistic behavior (e.g., covering a task for a sick IT professional) than civic virtue behavior (e.g., discussing how to improve organizational image on personal time). Thus, future research may extend the proposed model and examine the degree of each of five OCB sub-constructs exhibited by an IT professional.

\section{Conclusion}

This research systematically examined the impact of demographic variables including age, gender, and tenure on an IT professional's OCB. By incorporating these demographic variables and analyzing an understudied research population, this research provides insight into OCB exhibited by non-human service professionals. This research, therefore, enriches OCB and human resource management literature. The results confirmed the significant relationship between age and OCB and the significant relationship between tenure and OCB. Although this research is not without limitations especially with the use of a snowball sampling approach, it is expected that the findings and discussions of this research may be used by organizations and managers to establish a work environment where employees' OCB is maximized.

\section{References}

Allen, T. (2006). Rewarding good citizens: The relationship between citizenship behavior, gender, and organizational rewards. Journal of Applied Social Psychology, 36, 120-143.

Altuntas, S., \& Baykal, U. (2010). Relationship between nurses' organizational trust levels and their organizational citizenship behaviors. Journal of Nursing Scholarship, 42, 186-194.

Ang, S., Slaughter, S., \& Ng, K. Y. (2002). Human capital and institutional determinants of information technology compensation: Modeling multilevel and cross-level interactions. Management Science, 48, 1427-1445. 
Bateman, T., \& Organ, D. (1983). Job satisfaction and the good soldier: The relationship between affect and employee citizenship. Academy of Management Journal, 26, 587-595.

Belogolovsky, E., \& Somech, A. (2010). Teachers' organizational citizenship behavior: Examining the boundary between in-role behavior and extra-behavior from the perspective of teachers, principals and parents. Teaching and Teacher Education, 26, 914-923.

Bogler, R., \& Somech, A. (2004). Influence of teacher empowerment on teachers' organizational commitment, professional commitment and organizational citizenship in schools. Teaching and Teacher Education, 20, 277-289.

Caspi, A., \& Roberts, B. (1990). Personality continuity and change across the life course. In L. A. Pervin (Ed.), Handbook of personality theory and research (pp. 549-575). New York: Guilford,

Chiaburu, D., \& Lim, A. (2008). Manager trustworthiness or interactional justice? Predicting organizational citizenship behaviors. Journal of Business Ethics, 83, 453-467.

Chin, W. (1998). The partial least squares approach to structural equation modeling. In G. A. Marcoulides (Ed.), Modern methods for business research (pp. 295-336). Mahwah, NJ: Lawrence Erlbaum Associates.

Chin, W., Marcolin, B., \& Newsted, P. (2003). A partial least squares latent variable modeling approach for measuring interaction effects: Results from a Monte Carlo simulation study and an electronic-mail emotion/adoption study. Information Systems Research, 14, 189-217.

Chin, W., \& Newsted, P. (1999). Structural equation modeling analysis with small samples using partial least squares. In R. Hoyle (Ed.), Statistical strategies for small sample research (pp. 307-341).Thousand Oaks, CA: Sage Publications.

Choi, J. (2009). Collective dynamics of citizenship behavior: What group characteristics promote group-level helping? Journal of Management Studies, 46, 1396-1420.

Doering, M., Rhodes, S., \& Schuster, M. (1983). The aging worker. Beverly Hills, CA: Sage.

Ehigie, B., \& Otukoya, O. (2005). Antecedents of organizational citizenship behavior in a government-owned enterprise in Nigeria. European Journal of Work and Organizational Psychology, 14, 389-399.

Ehrhart, M., Bliese, P., \& Thomas, J. (2006). Unit-level OCB and unit effectiveness: Examining the incremental effect of helping behavior. Human Performance, 19, 159-173.

Eland-Goossensen, M. A., Van De Goor, L. A. M., Vollemans, E. C., Hendriks, V. M., \& Garretsen, H. E. L. (1997). Snowball sampling applied to Optiate addicts outside the treatment system. Addiction Research, 5, 317-330.

Farrell, S., \& Finkelstein, L. (2007). Organizational citizenship behavior and gender: Expectations and attributions for performance. North American Journal of Psychology, 9, 81-96.

Felfe, J., \& Heinitz, K. (2010). The impact of consensus and agreement of leadership 
perceptions on commitment, organizational citizenship behavior, and customer satisfaction. European Journal of Work and Organizational Psychology, 19, 279-303.

Fletcher, J. (1994). Castrating the female advantage: Feminist standpoint research and management science. Journal of Management Inquiry, 3, 74-82.

Fletcher, J. (1998). Relational practice: A feminist reconstruction of work. Journal of Management Inquiry, 7, 163-186.

Gallivan, M., Spitler, V., \& Koufaris, M. (2005). Does information technology training really matter? A social information processing analysis of coworkers' influence on IT usage in the workplace. Journal of Management Information Systems, 22, 153-192.

Golembiewski, R., \& Munzenrider, R. (1988). Phases of burnout. New York: Praeger Publishers.

Gurbuz, S. (2009). Some possible antecedents of military personnel organizational citizenship behavior. Military Psychology, 21, 200-215.

Heilman, M., \& Chen, J. (2005). Same behavior, difference consequences: Reactions to men's and women's altruistic citizenship behavior. Journal of Applied Psychology, 90, 431-441.

Hunt, S. (2002). On the virtues of staying "inside of the box": Does organizational citizenship behavior detract from performance in Taylorist Jobs. International Journal of Selection and Assessment, 10, 152-159.

Joseph, D., Ng, K., Koh, C., \& Ang, S. (2007). Turnover of information technology professionals: A narrative review, meta-analytic structural equation modeling, and model development. MIS Quarterly, 31, 547-577.

Kanungo, R., \& Conger, J. (1993). Promoting altruism as a corporate goal. Academy of Management Executive, 7, 37-48.

Koys, D. (2001). The effects of employee satisfaction, organizational citizenship behavior, and turnover on organizational effectiveness: A unit-level, longitudinal study. Personnel Psychology, 54, 101-114.

Lambert, S. (2000). Added benefits: The link between work-life benefits and organizational citizenship behavior. Academy of Management Journal, 43, 801-815.

Lapierre, L., \& Hackett, R. (2007). Trait conscientiousness, leader-member exchange, job satisfaction and organizational citizenship behavior: A test of an integrative model. Journal of Occupational and Organizational Psychology, 80, 539-554.

Lepine, J., \& Van Dyne, L. (2001). Peer responses to low performers: An attributional model of helping in the context of groups. Academy of Management Review, 26, 67-84.

Li, W., \& Wan, W. (2007). A demographic study on citizenship behavior as in-role orientation. Personality and Individual Differences, 42, 225-234. 
Liang, H., Saraf, N., Hu, Q., \& Xue, Y. (2007). Assimilation of enterprise systems: The effect of institutional pressures and the mediating role of top management. MIS Quarterly, 31, 59-87.

Lin, C. (2008). Clarifying the relationship between organizational citizenship behaviors, gender, and knowledge sharing in workplace organizations in Taiwan. Journal of Business and Psychology, 22, 241-250.

Martin, J., \& Dean, L. (1990). Developing a community sample of gay men for an epidemiologic study of AIDS. American Behavioral Scientist, 33, 546-561.

Mithas, S., \& Krishnan, M. S. (2008). Human capital and institutional effects in the compensation of information technology professionals in the United States. Management Science, 54, 415-428.

Moore, J. E., \& Love, M. (2005). IT professionals as organizational citizens. Communications of the ACM, 48, 89-93.

Moorman, R. (1993). The influence of cognitive and affective based job satisfaction measures on the relationship between satisfaction and organizational citizenship behavior. Human Relations, 46, 759-776.

Ng, T., \& Feldman, D. (2008). The relationship of age to ten dimensions of job performance. Journal of Applied Psychology, 93, 392-423.

Olsson, S., \& Walker, R. (2004). The wo-men and the boys: Patterns of identification and differentiation in senior women executives' representations of career identity. Women in Management Review, 19, 244-251.

Organ, D. (1988). Organizational citizenship behavior: The good soldier syndrome. Lexington, MA: Lexington Books.

Organ, D., Podsakoff, P., \& MacKenzie, S. (2006). Organizational citizenship behavior: Its nature, antecedents, and consequences. Thousand Oaks, CA: Sage.

Piron, F. (2006). China's changing culture: Rural and urban consumers' favorite things. Journal of Consumer Marketing, 23, 327-334.

Podsakoff, P., MacKenzie, S., Paine, J., \& Bachrach, D. (2000). Organizational citizenship behaviors: A critical review of the theoretical and empirical literature and suggestions for future research. Journal of Management, 26, 513-563.

Shtayermman, O. (2008). Suicidal ideation and Comorbid disorders in adolescents and young adults diagnosed with Asperger's syndrome: A population at risk. Journal of Human Behavior in the Social Environment, 18, 301-328.

Smith, A., Organ, D., \& Near, J. (1983). Organizational citizenship behavior: Its nature and antecedents. Journal of Applied Psychology, 68, 653-663.

Sparrowe, R., Liden, R., Wayne, S., \& Kraimer, M. (2001). Social networks and the 
performance of individuals and groups. Academy of Management Journal, 44, 316-325.

Stamper, C., \& Van Dyne, L. (2001). Work status and organizational citizenship behavior: A field study of restaurant employees. Journal of Organizational Behavior, 22, 517-536.

Trauth, E., Nielsen, S., \& von Hellens, L. (2003). Explaining the gender gap: Australian stories for the new millennium. Journal of Research and Practice in Information Technology, $35,7-20$.

Vanyperen, N., \& Van Den Berg, A. (1999). Towards a better understanding of the link between participation in decision-making and organizational citizenship behavior: A multilevel analysis. Journal of Occupational and Organizational Psychology, 72, 377-392.

Wagner, S., \& Rush, M. (2000). Altruistic organizational citizenship behavior: Context, disposition, and age. Journal of Social Psychology, 140, 379-391.

Whiting, S., Podsakoff, P., \& Pierce, J. (2008). Effects of task performance, helping, voice, and organizational loyalty on performance appraisal ratings. Journal of Applied Psychology, 93, 125-139.

Zikmund, W. (2003). Business Research Methods. (7th ed.). Mason, OH: South-Western. (Chapter 16).

\section{Appendix}

Appendix 1. Survey Questions for IT Professionals' OCB

Altruism

1. I help others who have heavy workloads.

2. I always help others who have been absent.

3. I am always willing to give my own time to help others with work problems.

Courtesy

Strongly

Disagree

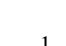

Neutral

Strongly

Agree

7

1

2
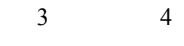

4$$
1
$$

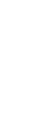

\footnotetext{
Courtesy

1. I take steps to prevent problems with other workers.

2. I always try to avoid creating problems for coworkers.

3. I do not abuse the rights of others.

4. I touch base with others before initiating actions.

5. I am generally mindful of how my own behavior affects other people's jobs.
}

\section{Strongly}

Disagree

Neutral

Strongly

Agree

3

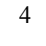

5

6

1
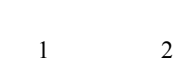

2

2

2 
Sportsmanship

Strongly

Disagree

Neutral

Strongly

1. I do not focus on what is wrong with my own situation.

2. (R) I spend a lot of time complaining about trivial matters.

3. I am not the classic "squeaky wheel" that always needs greasing.

4. I do not find fault with what my organization is doing.

5. I do not make "mountains out of molehills".

6. (R) I express resentment with any new changes in the organization that I work for.

\section{Conscientiousness}

1. I never take long lunches or breaks.

2. I do not take unnecessary time off work.

3. I do not take extra breaks.

4. My attendance at work is above the norm.

5. I typically obey my organization's rules and regulations even when no one is watching.

\section{Civic Virtue}

\section{Strongly}

Disagree

Neutral

Strongly 
Gender:

Years in the IT profession:

\section{Copyright Disclaimer}

Copyright reserved by the author(s).

This article is an open-access article distributed under the terms and conditions of the Creative Commons Attribution license (http://creativecommons.org/licenses/by/3.0/). 